\title{
Evaluation of irradiance and spectral output of visible light curing units used in the laboratory
}

\author{
Yoorina $\mathrm{Choi}^{1 \dagger}$, Su-Beom $\mathrm{Choi}^{2 \dagger}$, Ji-Hye Jung ${ }^{3}$, and Hoon-Sang Chang ${ }^{4 \star}$ \\ ${ }^{1}$ Assistant Professor, Department of Conservative Dentistry, College of Dentistry, Wonkwang University, Iksan, Republic of Korea \\ ${ }^{2}$ Ms.D. Student, Department of Dental Science, School of Dentistry, Chonnam National University, Gwangju, Republic of Korea \\ ${ }^{3}$ Associate Professor, Department of Prosthodontics, College of Dentistry, Wonkwang University, Iksan, Republic of Korea \\ ${ }^{4}$ Professor, Department of Conservative Dentistry, School of Dentistry, Chonnam National University, Gwangju, Republic of Korea
}

The irradiance of visible light curing units (LCUs) has been reported to decrease over time. However, the spectral output of used LCUs has rarely been evaluated. The purpose of this study was to evaluate the irradiance and the spectral output of visible LCUs used currently in laboratories. One halogen LCU (Optilux 360, O360), two polywave light emitting-diode (LED) LCUs (Bluephase Style [ST] and Bluephase G2 [G2]), and one single-peak LED LCU (Elipar S10, S10) were activated according to the manufacturers' instructions. The irradiance and spectral output of the curing light were measured with a spectroradiometer in real time $(n=10)$. Regarding the spectral peak and mean irradiance of the LCUs, O360 and G2 showed consistent data. However, ST showed spectral peaks at either 457 or $408 \mathrm{~nm}$, and S10 at either 456 or $450 \mathrm{~nm}$. The mean irradiance of ST and S10 was also inconsistent. Regarding the total energy, all LCUs surpassed the minimal energy value of $16 \mathrm{~J} / \mathrm{cm}^{2}$ to fully polymerize an increment of $2 \mathrm{~mm}$ of composite resin. However, focusing on 420-540 $\mathrm{nm}$ range energy where camphorquinone is activated, some data showed an energy value for ST of less than $16 \mathrm{~J} / \mathrm{cm}^{2}$, when the spectral peak was observed at $408 \mathrm{~nm}$. Therefore, to evaluate the performance of the LCUs, not only the irradiance but also the spectral output should be monitored, especially in the case of polywave LED LCUs, where multiple spectral peaks are present.

Key Words: Dental curing lights; Photoelectron spectroscopy; Spectrum analysis

(c) This is an open-access article distributed under the terms of the Creative Commons Attribution Non-Commercial License (http://creativecommons.org/licenses/by-nc/4.0) which permits unrestricted noncommercial use, distribution, and reproduction in any medium, provided the original work is properly cited.

\section{Introduction}

1976년에 할로겐 광중합기를 필두로 camphorquinone (CQ) 과 3차 아민을 이용한 광중합형 복합레진의 시대가 본격적으로 시작되었다[1]. 전형적인 할로겐 광중합기의 파장대는 약 400$550 \mathrm{~nm}$ 사이로 $\mathrm{CQ}$ 의 활성화 영역인 $470 \mathrm{~nm}$ 부근의 파장대를 포함하고 근래에 들어 사용이 증가하고 있는 2,4,6-Trimethylbenzoyldiphenylphosphine oxide (TPO), 1-phenyl-1,2- propanedione (PPD), Ivocerin과 같은 대체 광개시제의 활성 화 영역인 400-410 nm 범위의 파장대도 포함하며[2] 평균 조 도는 약 400-500 mW/cm²로 $2 \mathrm{~mm}$ 두께의 복합레진을 광중합 시키기 위해서는 40-60초의 광조사 시간이 요구되었다[1].

2000년대 들어서 높은 에너지 효율을 앞세워 가벼우면서도 이동성이 뛰어난 파란색 light emitting-diode (LED) 광중합기 가 개발되었다. 할로겐 전구와는 달리 파란색 LED 소자는 수명 이 수 천 시간에 이르기 때문에 교체할 필요가 없고, 오랜 시간

Received August 23, 2021; Revised September 9, 2021; Accepted October 1, 2021

*Corresponding author: Hoon-Sang Chang, Department of Conservative Dentistry, School of Dentistry, Chonnam National University, 33, Yongbong-ro, Buk-gu, Gwangju 61186, Republic of Korea.

Tel: +82-62-530-5860, Fax: +82-62-530-5590, E-mail: conden@jnu.ac.kr

${ }^{\dagger}$ These authors contributed equally to this work.

Copyright $\odot$ 2021, Oral Biology Research Institute 
사용하더라도 안정적인 출력을 나타내는 장점이 있다[2,3]. 초 기의 LED 광중합기는 기존의 할로겐 광중합기에 비해 조도가 낮았으나 스펙트럼 피크가 약 $470 \mathrm{~nm}$ 로 조도의 대부분이 CQ 의 활성화 범위에 집중되어 복합레진을 광중합할 때 할로겐 광 중합기와 비슷한 성능을 보였으나 파장대 범위가 좁아 대체 광 개시제를 활성화시키는 것은 불가능하였다[4].

2세대 LED 광중합기는 single-peak LED 광중합기라고도 하 며 고출력 LED 소자의 개발로 할로겐 광중합기 이상의 조도를 나타내어 복합레진의 광중합시간을 단축시키면서 본격적으로 할로겐 광중합기와 경쟁이 가능해졌고 지금도 여전히 많이 사 용되고 있다[1,4,5]. 중합광의 스펙트럼 피크는 1 세대 LED 광중 합기와 유사하나 파장대에 약간의 변화를 주어 일부 대체 광개 시제의 활성화 범위를 포함시켰다[2,6].

복합레진에서 대체 광개시제의 사용이 증가하면서 스펙트 럼 피크가 $460 \mathrm{~nm}$ 부근인 파란색 LED 소자에 스펙트럼 피크 가 $400 \mathrm{~nm}$ 부근인 보라색 LED 소자를 추가한 3세대 LED 광중 합기, 즉 polywave $\mathrm{LED}$ 광중합기가 등장하여 $\mathrm{CQ}$ 뿐만 아니라 대체 광개시제를 사용한 복합레진의 광중합도 가능하게 되었다 [2,6]. 하지만 보라색 LED 소자가 추가된 만큼 파란색 LED 소자 의 비중이 감소하여 $\mathrm{CQ}$ 의 활성화 영역에서의 에너지는 2 세대 $\mathrm{LED}$ 광중합기보다 감소되는 결과는 보였다[2].

광중합기는 사용 연한이 증가함에 따라 성능이 감소한다고 보고되었다[7,8]. 광조사 말단에 중합된 레진이 묻거나 광조사 말단이 깨지는 것이 일반적인 원인이고[2,9] 이를 예방하기 위 해서 광조사 말단에 일회용 차단막을 사용하거나 $[10,11]$ 광중 합기에 충격이 가해지지 않도록 주의해야 한다. 또한, 할로겐 광 중합기의 전구는 수명이 약 30-50시간으로 그 이상 사용하면 조도가 감소하며 대역 필터나 반사경 역시 노후화되면 교체해 야 하는 단점이 있다[1]. 2세대 또는 3세대 LED 광중합기의 경 우 조도를 증가시키거나 스펙트럼 피크를 두 개 이상 내기 위해 서 LED 소자를 집적시킨 결과 열이 많이 발생하기 때문에 LED 소자가 손상될 가능성이 있다[1]. 진료실에서 사용 중인 광중합 기를 평가한 이전의 많은 연구에서 조사광의 조도만을 측정하 였는데[3,8,9,12,13] polywave LED 광중합기와 같이 스펙트럼
피크가 2개 이상인 경우 광중합기의 조도 뿐만 아니라 파장대에 대한 분석도 필요해 보인다. $400 \mathrm{~nm}$ 부근에서의 조도가 아무리 크더라도 $460 \mathrm{~nm}$ 부근에서 반응하는 CQ을 활성화시킬 수 없 기 때문이다[9].

따라서 이번 연구의 목적은 현재 실험실에서 사용 중인 할로 겐 및 $\mathrm{LED}$ 광중합기의 조도 뿐만 아니라 파장대를 측정하고 분 석하여 광중합기의 성능을 평가하고자 하였다.

\section{Materials and Methods}

전남대학교 치의학전문대학원 치과보존학교실의 실험실에서 사용 중인 할로겐 광중합기인 Optilux 360 (O360), polywave LED 광중합기인 Bluephase Style (ST)과 Bluephase G2 (G2), 그리고 single-peak LED 광중합기인 Elipar S10 (S10)을 선택 하였다(Table 1). 모든 광중합기는 fiberoptic으로 제작된 광 조사 말단을 갖고 있으며 O360은 built-in radiometer를 장착 하고 있다. 각 광중합기를 spectroradiometer인 MARC resin calibrator (BlueLight Analytics, Halifax, NS, Canada)의 지지 대에 고정시키고 $4 \mathrm{~mm}$ 크기의 센서에 광중합기의 광조사 말단 이 접촉되게 위치 조정을 한 후에 standard mode로 제조사의 광조사 설정 시간에 따라 $\mathrm{O} 360$ 은 60초, 나머지 광중합기는 20 초 동안 광조사시켜 각 광중합기의 중합광을 실시간으로 분석 하였다 $(n=10)$. 각 광중합기의 파장과 조도 및 광조사 시간을 측 정하여 이를 바탕으로 광중합기가 광조사 시간 동안 방출하는 총 에너지를 계산하였고 부가적으로 $\mathrm{CQ}$ 을 활성화시키는 영역 인 420-540 nm 파장대의 에너지와 대체 광개시제를 활성화시 키는 영역인 360-420 nm 파장대의 에너지를 각각 분리하여 계 산하였다.

각 광중합기의 스펙트럼 피크(spectral peak), 평균 조도, 실 제 광조사 시간, 총 에너지, 420-540 nm 파장대의 에너지, 360-420 nm 파장대의 에너지 등은 유의수준 0.05에서 일원배 치 분산분석으로 통계분석한 후 Tukey's honestly significant difference test를 이용하여 사후 검정하였다(SPSS ver. 25.0; IBM, Armonk, NY, USA).

Table 1. Visible light curing units used in this study

\begin{tabular}{llllrl}
\hline \multirow{2}{*}{ Group } & Light curing unit & \multicolumn{1}{c}{ Manufacturer } & Type & $\begin{array}{c}\text { Tip diameter } \\
(\mathbf{m m})\end{array}$ & $\begin{array}{c}\text { Light curing time } \\
(\mathbf{s e c})\end{array}$ \\
\hline O360 & Optilux 360 & Demetron, Danbury, CT, USA & Halogen & 8 & 60 \\
G2 & Bluephase G2 & Ivoclar Vivadent, Schaan, Liechtenstein & Polywave LED & 10 & 20 \\
ST & Bluephase Style & Ivoclar Vivadent, Schaan, Liechtenstein & Polywave LED & 10 & 20 \\
S10 & Elipar S10 & 3M, St Paul, MN, USA & Single-peak LED & 10 & 20 \\
\hline
\end{tabular}

LED, light emitting-diode. 


\section{Results}

각 광중합기의 파장에 따른 조도(absolute irradiance)와 시간 에 따른 조도(irradiance)의 평균값을 이용하여 그린 그래프는 Fig. 1에 나타내었고 각 광중합기 별로 전체 데이터를 이용하여 그린 그래프는 Fig. 2에 나타내었다. 할로겐 광중합기인 $\mathrm{O} 360$ 은 넓은 파장대의 조사광을 낮은 조도로 긴 시간 동안 광조사하 였고(Fig. 1) 모든 데이터는 비교적 일정하게 측정되었다(Fig. 2A). Polywave LED 광중합기인 G2와 ST는 약 $408 \mathrm{~nm}$ 와 457 $\mathrm{nm}$ 에서 두 개의 스펙트럼 피크를 보였으며 $457 \mathrm{~nm}$ 에서의 조 도가 더 높았다. G2의 경우 모든 데이터가 비교적 일정하게 측 정된 반면(Fig. 2B) ST의 경우 스펙트럼 피크의 크기가 일관성이 없었다(Fig. 2C). Single-peak LED 광중합기인 S10은 비교적 좁은 파장대의 빛을 조사하였으며 $455 \mathrm{~nm}$ 에서 다른 광중합기 에 비해 매우 높은 조도 값을 보였다. 전체 데이터를 이용한 그 래프에서는 스펙트럼 피크의 형태와 조도 값이 일관적이지 않 았다(Fig. 2D).

각 광중합기의 스펙트럼 피크, 평균 조도, 실제 광조사 시간, 총 에너지, 420-540 nm 파장대의 에너지, 그리고 360-420 $\mathrm{nm}$ 파장대의 에너지 값은 Table 2에 나타내었다. 스펙트럼 피 크는 $\mathrm{O} 360$ 이 다른 LED 광중합기에 비해 통계적으로 유의하게 높았으며 LED 광중합기 간에는 유의차를 보이지는 않았다. 하 지만 ST에서는 다른 광중합기에 비해 표준편차가 큰 것이 관찰 되었다. 평균 조도는 $\mathrm{S} 10$ 이 다른 광중합기에 비해 유의하게 높 았고 표준편차 또한 크게 측정되었다. 그 다음으로 G2와 ST가 서로 유의차가 없었으나 ST에서는 표준편차가 크게 관찰되었 고 $\mathrm{O} 360$ 이 가장 낮게 측정되었다. 실제 광조사 시간은 $\mathrm{O} 360$ 이 설정 시간인 60 초보다 약간 짧았고, 설정 시간이 20초인 나머 지 LED 광중합기는 설정 시간보다 약간 길게 광조사가 진행되
었다. 중합광의 총 에너지는 S10이 유의하게 높았고 뒤를 이어 $\mathrm{G} 2, \mathrm{ST}$, 그리고 $\mathrm{O} 360$ 이 유의차 없이 측정되었으나 S10과 ST에 서는 비교적 큰 표준편차를 보였다. 420-540 nm 파장대의 에 너지는 $\mathrm{S} 10$ 이 유의하게 높았고 뒤를 이어 G2와 $\mathrm{O} 360$ 이 서로 간의 유의차가 없었으며 ST가 가장 낮게 계산되었다. S10과 ST 에서는 비교적 큰 표준편차가 관찰되었다. 360-420 nm 파장 대의 에너지는 ST가 가장 높았고 표준편차 또한 컸으며 G2와 $\mathrm{O} 360$ 이 각각 뒤를 이었고, $\mathrm{S} 10$ 이 가장 낮게 계산되었다.

추가적으로 스펙트럼 피크와 평균 조도, 그리고 에너지 값 에서 표준편차가 크게 계산된 ST와 S10에 대해서 전체 데이터 를 분석하였다. ST의 파장에 따른 조도 그래프(Fig. $2 \mathrm{C}$ )에서 약 $457 \mathrm{~nm}$ 에서 스펙트럼 피크를 갖는 데이터(ST_1)와 약 $408 \mathrm{~nm}$ 에서 스펙트럼 피크를 갖는 데이터(ST_2)를 각각 두 그룹으로 설정하여 independent t-test를 이용하여 통계 분석하였을 때 평균 조도와 총 에너지가 ST_1이 ST_2보다 유의하게 큰 것으로 관찰되었고 스펙트럼 피크의 크기에 비례하여 ST_1은 420-540 $\mathrm{nm}$ 파장대의 에너지가 유의하게 크고 ST_2는 360-420 nm 파 장대의 에너지가 유의하게 크게 계산되었다 $(p<0.05$, Table 3$)$. $\mathrm{S} 10$ 의 파장에 따른 조도 그래프(Fig. 2D) 상에서도 자연스러 운 형태의 $456 \mathrm{~nm}$ 에서 스펙트럼 피크를 보인 데이터(S10_1) 와 일그러진 형태의 $450 \mathrm{~nm}$ 에서 스펙트럼 피크를 보인 데이터 (S10_2)를 두 그룹으로 설정하여 independent t-test를 이용하 여 통계 분석하였을 때 평균 조도와 총 에너지, 그리고 420-540 $\mathrm{nm}$ 파장대의 에너지가 S10_1이 S10_2보다 유의하게 더 큰 것 으로 계산되었고 $(p<0.05) 360-420 \mathrm{~nm}$ 파장대의 에너지에는 통계적 유의차가 관찰되지 않았다 $(p>0.05$, Table 4).
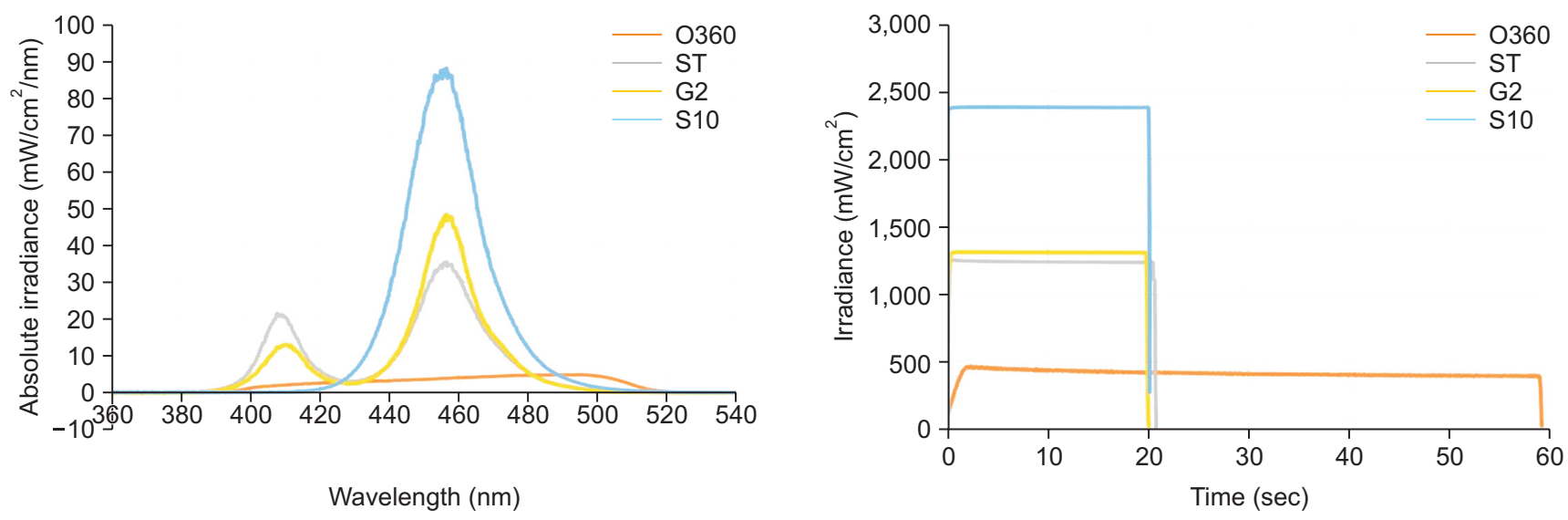

Fig. 1. Mean absolute irradiance according to wavelength (left) and mean irradiance according to time (right) of tested light curing units. O360, Optilux 360; ST, Bluephase Style; G2, Bluephase G2; S10, Elipar S10. 
A
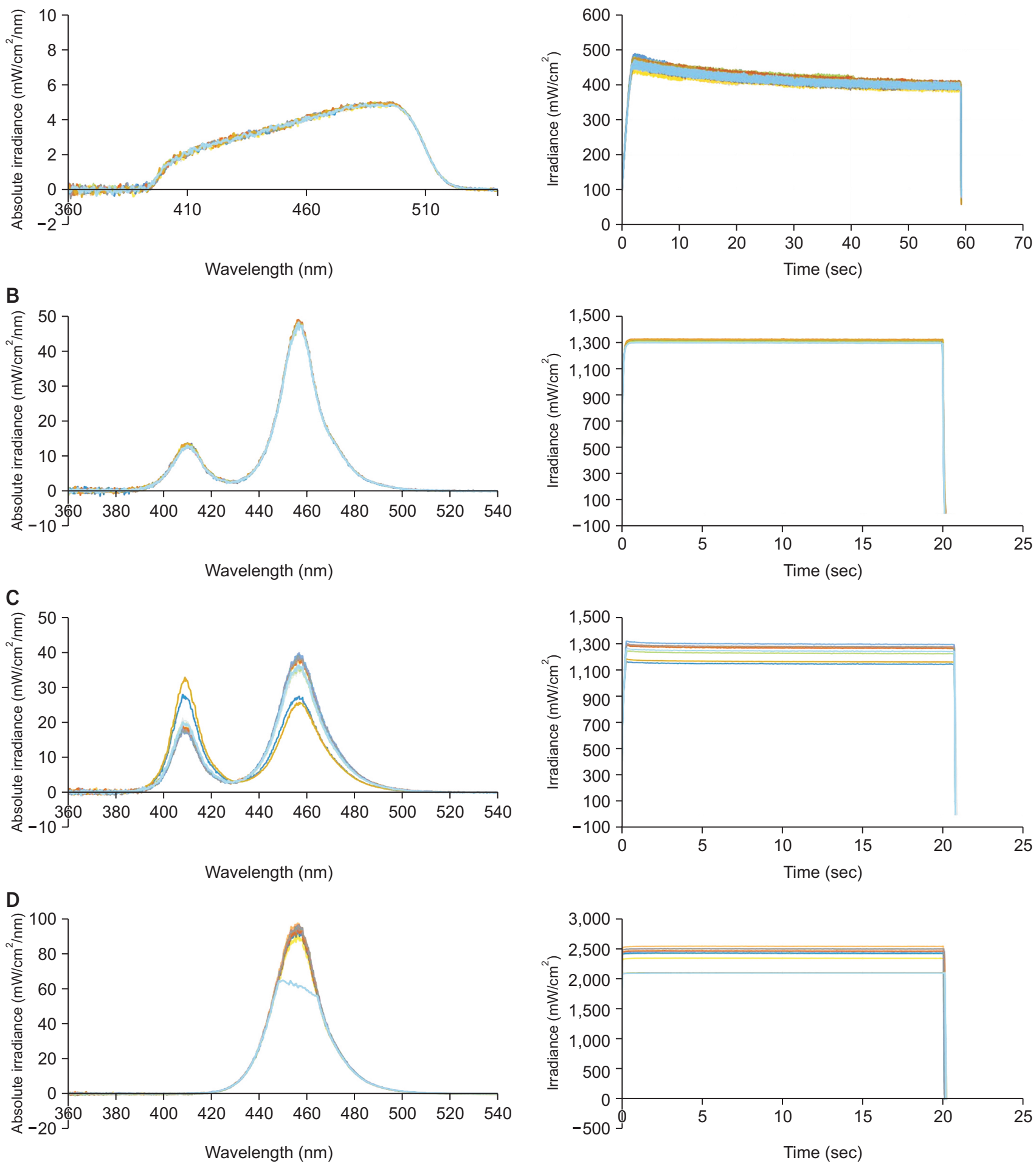

Fig. 2. Mean absolute irradiance according to wavelength (left) and mean irradiance according to time (right) using raw data of tested light curing units. (A) O360, (B) G2, (C) ST, (D) S10. O360, Optilux 360; G2, Bluephase G2; ST, Bluephase Style; S10, Elipar S10. 
Table 2. Spectral peak, mean irradiance, optical curing time, and energy of tested light curing units

\begin{tabular}{lcccccc}
\hline Group & $\begin{array}{c}\text { Spectral peak } \\
(\mathbf{n m})\end{array}$ & $\begin{array}{c}\text { Mean irradiance } \\
\left(\mathbf{m W} / \mathbf{c m}^{2}\right)\end{array}$ & $\begin{array}{c}\text { Optical curing } \\
\text { time }(\mathbf{s e c})\end{array}$ & $\begin{array}{c}\text { Total energy } \\
\left(\mathbf{J} / \mathbf{c m}^{2}\right)\end{array}$ & $\begin{array}{c}\mathbf{4 2 0}-\mathbf{5 4 0} \mathbf{~ n m ~ r a n g e} \\
\text { energy }\left(\mathbf{J} / \mathbf{c m}^{2}\right)\end{array}$ & $\begin{array}{c}\mathbf{3 6 0}-\mathbf{4 2 0} \mathbf{~ n m ~ r a n g e} \\
\mathbf{e n e r g y}\left(\mathbf{J} / \mathbf{c m}^{2}\right)\end{array}$ \\
\hline O360 & $490 \pm 4^{\mathrm{a}}$ & $413 \pm 5^{\mathrm{c}}$ & $59.18 \pm 0.02^{\mathrm{a}}$ & $24.44 \pm 0.27^{\mathrm{b}}$ & $21.72 \pm 0.20^{\mathrm{b}}$ & $2.72 \pm 0.09^{\mathrm{c}}$ \\
G2 & $457 \pm 1^{\mathrm{b}}$ & $1,299 \pm 11^{\mathrm{b}}$ & $20.13 \pm 0.02^{\mathrm{d}}$ & $26.17 \pm 0.24^{\mathrm{b}}$ & $22.02 \pm 0.18^{\mathrm{b}}$ & $4.15 \pm 0.12^{\mathrm{b}}$ \\
ST & $447 \pm 20^{\mathrm{b}}$ & $1,232 \pm 50^{\mathrm{b}}$ & $20.78 \pm 0.03^{\mathrm{b}}$ & $25.61 \pm 1.04^{\mathrm{b}}$ & $19.23 \pm 2.36^{\mathrm{c}}$ & $6.38 \pm 1.37^{\mathrm{a}}$ \\
S10 & $455 \pm 3^{\mathrm{b}}$ & $2,367 \pm 157^{\mathrm{a}}$ & $20.18 \pm 0.04^{\mathrm{c}}$ & $47.77 \pm 3.16^{\mathrm{a}}$ & $47.52 \pm 3.15^{\mathrm{a}}$ & $0.25 \pm 0.02^{\mathrm{d}}$ \\
\hline
\end{tabular}

Values are presented as mean \pm standard deviation.

O360, Optilux 360; ST, Bluephase Style; G2, Bluephase G2; S10, Elipar S10.

Mean values followed by different small letters (column) are significantly different by Tukey's HSD test $(\alpha=0.05)$.

Table 3. Spectral peak, mean irradiance, optical curing time, and energy of ST according to spectral peak

\begin{tabular}{|c|c|c|c|c|c|}
\hline Group & $\begin{array}{l}\text { Spectral peak } \\
(\mathbf{n m})\end{array}$ & $\begin{array}{c}\text { Mean irradiance } \\
\left(\mathrm{mW} / \mathrm{cm}^{2}\right)\end{array}$ & $\begin{array}{l}\text { Total energy } \\
\left(\mathrm{J} / \mathrm{cm}^{2}\right)\end{array}$ & $\begin{array}{c}420-540 \mathrm{~nm} \\
\text { range energy }\left(\mathrm{J} / \mathrm{cm}^{2}\right)\end{array}$ & $\begin{array}{c}360-420 \mathrm{~nm} \\
\text { range energy }\left(\mathrm{J} / \mathrm{cm}^{2}\right)\end{array}$ \\
\hline ST_1 & $457 \pm 1^{\mathrm{a}}$ & $1,253 \pm 26^{\mathrm{a}}$ & $26.06 \pm 0.53^{\mathrm{a}}$ & $20.30 \pm 0.80^{\mathrm{a}}$ & $5.76 \pm 0.31^{\mathrm{b}}$ \\
\hline ST_2 & $408 \pm 1^{\mathrm{b}}$ & $1,148 \pm 12^{\mathrm{b}}$ & $23.85 \pm 0.24^{\mathrm{b}}$ & $14.97 \pm 0.63^{\mathrm{b}}$ & $8.83 \pm 0.86^{\mathrm{a}}$ \\
\hline
\end{tabular}

Values are presented as mean \pm standard deviation.

ST, Bluephase Style.

Mean values followed by different small letters (column) are significantly different $(\alpha=0.05)$.

Table 4. Spectral peak, mean irradiance, optical curing time, and energy of S10 according to spectral peak

\begin{tabular}{|c|c|c|c|c|c|}
\hline Group & $\begin{array}{l}\text { Spectral peak } \\
(\mathrm{nm})\end{array}$ & $\begin{array}{l}\text { Mean irradiance } \\
\left(\mathrm{mW} / \mathrm{cm}^{2}\right)\end{array}$ & $\begin{array}{l}\text { Total energy } \\
\left(\mathrm{J} / \mathrm{cm}^{2}\right)\end{array}$ & $\begin{array}{c}420-540 \mathrm{~nm} \\
\text { range energy }\left(\mathrm{J} / \mathrm{cm}^{2}\right)\end{array}$ & $\begin{array}{c}360-420 \mathrm{~nm} \\
\text { range energy }\left(\mathrm{J} / \mathrm{cm}^{2}\right)\end{array}$ \\
\hline S10_1 & $456 \pm 1^{\mathrm{a}}$ & $2,437 \pm 61^{\mathrm{a}}$ & $49.18 \pm 1.23^{\mathrm{a}}$ & $48.93 \pm 1.21^{\mathrm{a}}$ & $0.25 \pm 0.02^{\mathrm{a}}$ \\
\hline S10_2 & $450 \pm 1^{\mathrm{b}}$ & $2,087 \pm 1^{\mathrm{b}}$ & $42.13 \pm 0.05^{\mathrm{b}}$ & $41.90 \pm 0.05^{\mathrm{b}}$ & $0.23 \pm 0.01^{\mathrm{a}}$ \\
\hline
\end{tabular}

Values are presented as mean \pm standard deviation.

S10, Elipar S10.

Mean values followed by different small letters (column) are significantly different $(\alpha=0.05)$.

\section{Discussion}

광중합기의 조사광은 일관성이 있어야 사용자가 복합레진 의 광중합을 예측할 수 있다. 특히 구치부 인접면의 깊은 와동 을 직접 수복할 때와 같이 광조사 말단과 복합레진과의 거리가 멀거나 세라믹 수복물 하방의 레진시멘트를 광중합할 때와 같 이 간접수복물에 의해 조사광이 약화되는 경우에서 광중합기 의 조사광이 일관적이지 않다면 약화된 조사광을 보상하기 위 해 추가로 증가시켜야하는 광조사 시간을 계산하기 어려워진다 [14,15]. 심지어 광개시제를 활성화시키는 영역의 조사광이 일 관성 있게 유지되지 않고 일정 수준 이하로 감소한다면 광조사 시간을 아무리 늘리더라도 복합레진의 광중합이 충분히 일어나 지 않을 수도 있다[2].

이번 실험에서 측정한 스펙트럼 피크는 조사광의 파장 중 가 장 높은 조도를 나타내는 파장을 가리킨다. 할로겐 광중합기인 $\mathrm{O} 360$ 은 파장에 따른 조도가 LED 광중합기에 비해 현저히 낮은
반면 약 400-520 nm에 걸쳐 넓은 파장대의 조사광이 측정되었 고 스펙트럼 피크는 $490 \mathrm{~nm}$ 에서 관찰되었다. 이는 대부분의 복 합레진에 사용되는 광개시제인 $\mathrm{CQ}$ 이나 일부 복합레진에 사용 되는 대체 광개시제를 활성화시키에 충분하다[1]. LED 광중합 기인 G2, S10, ST는 통계적 유의차 없이 447-457 nm 사이에 서 스펙트럼 피크를 보여 $\mathrm{CQ}$ 이 활성화되는 파장대의 조사광을 포함하였다. 그 중에서 polywave LED 광중합기인 G2와 ST는 $410 \mathrm{~nm}$ 전후로 또 하나의 스펙트럼 피크가 관찰되어 대체 광개 시제가 활성화되는 파장대의 조사광을 포함하였다. 하지만 G2 의 경우 $410 \mathrm{~nm}$ 부근에서 작은 스펙트럼 피크와 $457 \mathrm{~nm}$ 부근 에서 큰 스펙트럼 피크가 일관성 있게 관찰된 반면(Fig. 2B) ST 의 경우에서는 $410 \mathrm{~nm}$ 부근과 $457 \mathrm{~nm}$ 부근에서 스펙트럼 피 크의 크기가 일관적이지 않았다(Fig. $2 \mathrm{C}$ ). 제조사에 의하면 G2 는 $410 \mathrm{~nm}$ 부근의 빛을 내는 보라색 LED 소자 1 개와 $457 \mathrm{~nm}$ 부근의 빛을 내는 파란색 LED 소자 3개로 구성되어 있고 ST의 경우 보라색 LED 소자 1 개와 파란색 LED 소자 2 개로 구성되어 
있다고 하였는데[16], 이를 뒷받침하듯이 G2의 그래프에서는 $410 \mathrm{~nm}$ 부근의 스펙트럼 피크에 비해 $457 \mathrm{~nm}$ 부근의 스펙트 럼 피크가 약 3배 정도 크게 관찰되었다(Fig. 2B). ST의 그래프 에서는 대부분의 데이터에서 $408 \mathrm{~nm}$ 부근의 스펙트럼 피크에 비해 $457 \mathrm{~nm}$ 부근의 스펙트럼 피크가 약 2배 정도 크게 관찰되 어 제조사의 설명을 뒷받침하였으나 몇몇의 데이터에서는 408 $\mathrm{nm}$ 부근의 스펙트럼 피크가 $457 \mathrm{~nm}$ 부근의 스펙트럼 피크보 다 더 크게 관찰되기도 하였다(Fig. 2C). 이로 인해 ST의 스펙트 럼 피크의 평균 값이 $\mathrm{G} 2$ 보다 약 $10 \mathrm{~nm}$ 더 낮고 표준편차는 크 게 계산되었다(Table 2). Single-peak LED 광중합기인 S10의 경우 약 420-500 nm의 파장대의 조사광이 측정되어 400-410 $\mathrm{nm}$ 에서 활성화되는 대체 광개시제의 사용에는 제한이 따를 것 으로 판단된다. S10의 데이터 대부분은 $456 \mathrm{~nm}$ 에서 스펙트럼 피크를 보였으나 몇몇의 데이터는 약 $450 \mathrm{~nm}$ 에서 스펙트럼 피 크가 다소 일그러진 형태로 관찰되었으며 이로 인해 총 에너지 도 다소 감소된 모습을 보였다(Fig. 2D). Pelissier 등[4]은 조사 광이 강한 single-peak LED 광중합기와 polywave LED 광중합 기에서 여러 개의 LED 소자를 동시에 작동시킬 경우 조도가 불 안정해질 수 있으며 과열로 인해 조도가 감소하거나 스펙트럼 의 이동(spectral shift)이 일어나기도 하며 LED 소자가 일시적 이거나 영구적으로 손상되는 경우도 있다고 하였다. ST의 경우 $\mathrm{LED}$ 소자에 공급되는 전압이나 전류의 문제로 인해 $410 \mathrm{~nm}$ 부 근의 빛을 내는 LED 소자의 조도가 증가한 반면 $457 \mathrm{~nm}$ 부근 의 빛을 내는 LED 소자의 조도가 감소했을 가능성이 있으며[17] $\mathrm{S} 10$ 의 경우 과열로 인해 LED 소자가 일시적으로 손상되어 스펙 트럼 피크의 형태가 일그러지고 조도 또한 감소되었을 것으로 추측된다.

평균 조도는 $\mathrm{O} 360$ 이 $413 \mathrm{~mW} / \mathrm{cm}^{2}$ 로 가장 낮았으나 $2 \mathrm{~mm}$ 두께의 복합레진을 광중합시기키 위해 필요한 ISO 기준인 300 $\mathrm{mW} / \mathrm{cm}^{2}[6,18,19]$ 또는 여러 연구에서 주장한 최소 조도인 $400 \mathrm{~mW} / \mathrm{cm}^{2}[9,20,21]$ 보다 높게 측정되어 위의 기준을 모두 상회하였다. 대신에 낮은 조도를 보완하기 위해 광조사 시간이 60초로 설정되어 다른 LED 광중합기의 광조사 설정 시간인 20 초보다 월등히 길었다. LED 광중합기들은 $\mathrm{O} 360$ 보다 높은 평균 조도를 보였는데 그 중에서도 single-peak 광중합기인 S10은 polywave 광중합기인 G2나 ST보다도 유의하게 더 높은 평균 조도를 보였다. S10의 경우 파란색 LED 소자만을 사용한 반편 $\mathrm{G} 2$ 와 ST의 경우 보라색 LED 소자가 추가된 만큼 파란색 LED 소자의 비중이 줄어들었기 때문인 것으로 판단된다[2].

실제 측정된 광조사 시간은 $\mathrm{O} 360$ 의 경우 설정 시간인 60초 에 약간 못 미쳤지만 총 에너지는 $24 \mathrm{~J} / \mathrm{cm}^{2}$ 이상으로 계산되 어 $2 \mathrm{~mm}$ 두께의 복합레진을 중합시키는데 필요한 최소 에너지 인 $16 \mathrm{~J} / \mathrm{cm}^{2}$ 보다 월등히 큰 값을 보였다[9,22]. G2와 ST의 경
우 $\mathrm{O} 360$ 보다 평균 조도가 약 3 배 더 크기 때문에 광조사 시간 이 $\mathrm{O} 360$ 보다 $1 / 3$ 정도 짧은 20 초로 감소했음에도 불구하고 총 에너지에서는 통계적 유의차를 보이지 않았다. S10의 경우 평균 조도가 ST보다 약 2배 정도 크기 때문에 20초 동안 광조사했을 때 총 에너지도 약 2 배 정도 크게 계산되었다.

총 에너지를 $\mathrm{CQ}$ 이 활성화되는 영역에서의 에너지와 대체 광 개시제가 활성화되는 영역에서의 에너지로 나누어 살펴보았을 때 총 에너지가 가장 큰 single-peak 광중합기인 S10의 경우 약 $99 \%$ 가 CQ의 활성화 영역의 에너지였으며 polywave LED 광 중합기인 G2의 경우 약 $84 \%$, ST의 경우 약 $75 \%$, 그리고 할로겐 광중합기인 $\mathrm{O} 360$ 의 경우 전체 에너지의 약 $89 \%$ 가 이에 해당되 었다. CQ의 활성화 영역의 에너지 비중이 가장 낮은 ST의 경우 에너지가 $19.23 \pm 2.36 \mathrm{~J} / \mathrm{cm}^{2}$ 로 측정되었으나 스펙트럼 피크가 $408 \mathrm{~nm}$ 로 측정된 ST_2의 데이터만 고려한다면 CQ 영역의 에 너지가 $14.97 \pm 0.63 \mathrm{~J} / \mathrm{cm}^{2}$ 로 측정되어 $2 \mathrm{~mm}$ 두께의 복합레진 을 중합시키는데 필요한 최소 에너지인 $16 \mathrm{~J} / \mathrm{cm}^{2}$ 보다 낮게 계 산되었다. 물론 ST_2의 총 에너지는 $23.85 \pm 0.24 \mathrm{~J} / \mathrm{cm}^{2}$ 로 $16 \mathrm{~J} /$ $\mathrm{cm}^{2}$ 보다 확연히 크지만 대체 광개시제의 활성화 영역의 에너지 가 $\mathrm{CQ}$ 의 활성화에 별로 도움이 되지 않는다는 것을 감안한다면 광중합시간을 늘려 $\mathrm{CQ}$ 의 활성화 영역의 에너지를 증가시켜야 할 수도 있을 것이다.

반대로 대체 광개시제를 활성화시키는 영역의 에너지를 보 면 polywave LED 광중합기인 ST와 G2가 약 $25 \%$ 와 약 $16 \%$ 로 그 비중이 가장 컸으며 할로겐 광중합기인 $\mathrm{O} 360$ 이 약 $11 \%$ 그 리고 single-peak LED 광중합기인 S10은 약 $1 \%$ 만이 해당 영역 의 에너지로 계산되었다. ST와 G2의 차이는 보라색 LED 소자 와 파란색 LED 소자의 비율의 차이로 보이고, 할로겐 광중합기 인 $\mathrm{O} 360$ 의 경우 보라색 부근에서의 조도가 파란색 부근에서의 조도보다 낮기 때문에 별도의 스펙트럼 피크가 있는 polywave LED 광중합기보다 더 낮게 계산되었다. Single-peak LED 광중 합기인 S10의 경우 $410 \mathrm{~nm}$ 부근의 빛을 내는 LED 소자가 탑 재되어 있지 않아 대체 광개시제를 활성화시키기에는 적절하지 않을 것으로 판단된다.

이번 연구에서 사용한 할로겐 광중합기인 $\mathrm{O} 360$ 은 $2 \mathrm{~mm}$ 두 께의 복합레진을 광중합시키기 위해 필요한 최소값 이상의 조 도와 넓은 범위의 파장대가 일관성 있게 측정되었고 polywave $\mathrm{LED}$ 광중합기인 G2 역시 충분한 조도와 $408 \mathrm{~nm}$ 와 $457 \mathrm{~nm}$ 에 서 일관성이 있는 스펙트럼 피크를 보였다. 이에 반해 또 다른 polywave LED 광중합기인 ST의 경우 복합레진의 광중합에 필 요한 최소 조도와 에너지 값을 상회하였으나 파장대를 분석한 결과 스펙트럼 피크가 $408 \mathrm{~nm}$ 에서 나타날 경우 $\mathrm{CQ}$ 의 활성화 영역의 에너지가 복합레진을 광중합시키기 위한 최소 에너지보 다 더 낮게 계산되었다. 또한, single-peak LED 광중합기인 S10 
의 경우 조도와 $\mathrm{CQ}$ 의 활성화 영역의 에너지가 충분히 높게 나 타났으나 스펙트럼 피크가 일관적이지 못하여 조도와 총 에너 지 및 $\mathrm{CQ}$ 의 활성화 영역의 에너지의 편차가 크게 측정되었다. 이와 같이 광중합기의 파장대가 일관성을 보이지 않을 때 $\mathrm{CQ}$ 의 활성화에 영향을 미치는지와 광중합기의 조도의 감소가 광조사 말단과 복합레진과의 거리가 증가한 경우에 복합레진의 광중합 에 영향을 미치는지에 대한 후속 연구가 필요할 것으로 생각된 다. 요약하자면, 최근에 출시된 polywave LED 광중합기를 평가 할 때 조도만 측정할 경우 $\mathrm{CQ}$ 을 활성화시키는 영역의 에너지가 기준치 이하로 감소하더라도 대체 광개시제를 활성화시키는 영 역의 에너지가 비정상적으로 커진다면 광중합기의 조도가 기준 치 이상으로 측정될 수 있기 때문에 광중합기를 주기적으로 점 검할 때는 조사광의 조도뿐만 아니라 파장대도 같이 측정하여 파장대에 따른 조도가 적절한지 평가해야 한다.

\section{Conflicts of Interest}

The authors declare that they have no competing interests.

\section{ORCID}

\author{
Yoorina Choi \\ https://orcid.org/0000-0001-6869-8562 \\ Su-Beom Choi \\ https://orcid.org/0000-0003-2335-2407 \\ Ji-Hye Jung \\ https://orcid.org/0000-0003-3322-4011 \\ Hoon-Sang Chang \\ https://orcid.org/0000-0002-3019-1528
}

\section{References}

1. Rueggeberg FA. State-of-the-art: dental photocuring-a review. Dent Mater 2011;27:39-52. doi: 10.1016/ j.dental.2010.10.021.

2. Rueggeberg FA, Giannini M, Arrais CAG, Price RBT. Light curing in dentistry and clinical implications: a literature review. Braz Oral Res 2017;31 Suppl 1:e61. doi: 10.1590/1807-3107BOR-2017.vol31.0061.

3. Hao X, Luo M, Wu J, Zhu S. A survey of power density of light-curing units used in private dental offices in Changchun City, China. Lasers Med Sci 2015;30:493-497. doi: 10.1007/s10103-013-1351-0.

4. Pelissier B, Jacquot B, Palin WM, Shortall AC. Three generations of LED lights and clinical implications for op- timizing their use. 1: from past to present. Dent Update 2011;38:660-662, 664-666, 668-670. doi: 10.12968/ denu.2011.38.10.660.

5. Uhl A, Sigusch BW, Jandt KD. Second generation LEDs for the polymerization of oral biomaterials. Dent Mater 2004;20:80-87. doi: 10.1016/s0109-5641(03)00095-2.

6. Soares CJ, Rodrigues MP, Oliveira LRS, Braga SSL, Barcelos LM, Silva GRD, Giannini M, Price RB. An evaluation of the light output from 22 contemporary light curing units. Braz Dent J 2017;28:362-371. doi: 10.1590/01036440201601466.

7. Park LC, Choi YS, Kim KN. The condition of light curing units used in dental clinics in Seoul, Korea. J Korean Res Soc Dent Mater 1995;22:159-166.

8. Maghaireh GA, Alzraikat H, Taha NA. Assessing the irradiance delivered from light-curing units in private dental offices in Jordan. J Am Dent Assoc 2013;144:922-927. doi: 10.14219/jada.archive.2013.0210.

9. Ernst CP, Price RB, Callaway A, Masek A, Schwarm H, Rullmann I, Willershausen B, Ehlers V. Visible light curing devices - irradiance and use in 302 German dental offices. J Adhes Dent 2018;20:41-55. doi: 10.3290/j.jad.a39881.

10. Chang HS, Lee SR, Hong SO, Ryu HW, Song CK, Min KS. Effect of infection control barrier thickness on light curing units. J Korean Acad Conserv Dent 2010;35:368-373. doi: 10.5395/JKACD.2010.35.5.368.

11. Hwang IN, Hong SO, Lee BN, Hwang YC, Oh WM, Chang HS. Effect of a multi-layer infection control barrier on the micro-hardness of a composite resin. J Appl Oral Sci 2012;20:576-580. doi: 10.1590/s167877572012000500014.

12. Miyazaki M, Hattori T, Ichiishi Y, Kondo M, Onose H, Moore BK. Evaluation of curing units used in private dental offices. Oper Dent 1998;23:50-54.

13. El-Mowafy O, El-Badrawy W, Lewis DW, Shokati B, Soliman O, Kermalli J, Encioiu A, Rajwani F, Zawi R. Efficacy of halogen photopolymerization units in private dental offices in Toronto. J Can Dent Assoc 2005;71:587.

14. Peutzfeldt A, Asmussen E. Resin composite properties and energy density of light cure. J Dent Res 2005;84:659-662. doi: $10.1177 / 154405910508400715$.

15. Seth S, Lee CJ, Ayer CD. Effect of instruction on dental students' ability to light-cure a simulated restoration. J Can Dent Assoc 2012;78:c123.

16. Shim YB, Choi AN, Park JK. Characteristic of LED light curing unit and classification by generation for clinicians. J Dent Rehabil Appl Sci 2017;33:245-251. doi: 10.14368/ jdras.2017.33.4.245.

17. Fan PL, Wozniak WT, Reyes WD, Stanford JW. Irradiance of visible light-curing units and voltage variation effects. J Am Dent Assoc 1987;115:442-445. doi: 10.14219/jada. archive.1987.0252.

18. Fan PL, Schumacher RM, Azzolin K, Geary R, Eichmiller 
FC. Curing-light intensity and depth of cure of resin-based composites tested according to international standards. J Am Dent Assoc 2002;133:429-434; quiz 491-493. doi: 10.14219/jada.archive.2002.0200.

19. Al Shaafi M, Maawadh A, Al Qahtani M. Evaluation of light intensity output of QTH and LED curing devices in various governmental health institutions. Oper Dent 2011;36:356361. doi: 10.2341/10-247-O.

20. Yap AU, Seneviratne C. Influence of light energy density on effectiveness of composite cure. Oper Dent 2001;26:460-
466.

21. Rueggeberg FA, Caughman WF, Curtis JW Jr. Effect of light intensity and exposure duration on cure of resin composite. Oper Dent 1994;19:26-32.

22. Beolchi RS, Moura-Netto C, Palo RM, Rocha Gomes Torres $\mathrm{C}$, Pelissier B. Changes in irradiance and energy density in relation to different curing distances. Braz Oral Res 2015;29:S1806-83242015000100257. doi: 10.1590/18073107BOR-2015.vol29.0060. 